\title{
Arterial pH and Blood Gas Values in Rats Under Three Types of General Anesthesia: a Chronobiological Study
}

\author{
P. SVORC ${ }^{1}$, D. PETRÁŠOVÁ ${ }^{2}$, P. SVORC Jr. ${ }^{3}$ \\ ${ }^{1}$ Department of Physiology, Medical Faculty Safarik’s University, Kosice, Slovak Republic, \\ ${ }^{2}$ Laboratory of Research Bio-models, Medical Faculty Safarik's University, Kosice, Slovak \\ Republic, ${ }^{3}$ Department of Physiology and Pathophysiology, Medical Faculty Ostrava University, \\ Ostrava, Czech Republic
}

Received June 19, 2017

Accepted April 25, 2018

On-line July 25, 2018

\section{Summary}

The aim of study was to review the status of arterial $\mathrm{pH}, \mathrm{pO}_{2}$ and $\mathrm{PCO}_{2}$ under general anesthesias in dependence on the light-dark (LD) cycle in spontaneously breathing rats. The experiments were performed using three- to four-month-old pentobarbital(P)-, ketamine/xylazine(K/X)- and zoletil(Z)-anesthetized female Wistar rats after a four-week adaptation to an LD cycle (12 h light: $12 \mathrm{~h}$ dark). The animals were divided into three experimental groups according to the anesthetic agent used: $P$ (light $n=11$; dark $\mathrm{n}=8$ ); $\mathrm{K} / \mathrm{X}$ (light $\mathrm{n}=13$; dark $\mathrm{n}=11$ ); and $\mathrm{Z}$ (light $\mathrm{n}=18$; dark $\mathrm{n}=26$ ). $\mathrm{pH}$ and blood gases from arterial blood were analyzed. In $\mathrm{P}$ anesthesia, $\mathrm{LD}$ differences in $\mathrm{pH}, \mathrm{pO}_{2}$, and $\mathrm{pCO}_{2}$ were eliminated. In $\mathrm{K} / \mathrm{X}$ anesthesia, parameters showed significant LD differences. In $\mathrm{Z}$ anesthesia, LD differences were detected for $\mathrm{pH}$ and $\mathrm{pO}_{2}$ only. Acidosis, hypoxia, and hypercapnia have been reported for all types of anesthesia during the light period. In the dark period, except for $\mathrm{P}$ anesthesia, the environment was more stable and values fluctuated within normal ranges. From a chronobiological perspective, $\mathrm{P}$ anesthesia was not the most appropriate type of anesthesia in these rat experiments. It eliminated LD differences, and also produced a more acidic environment and more pronounced hypercapnia than $\mathrm{K} / \mathrm{X}$ and $\mathrm{Z}$ anesthesias.

\section{Key words}

Chronobiology • Anesthesia $\bullet \mathrm{pH} \bullet$ Blood gases $\bullet$ Rats

\section{Corresponding author}

P. Švorc, Department of Physiology, Medical Faculty, Pavol Josef Šafárik University, Tr. SNP 1, 04001 Košice, Slovak Republic. E-mail: pavol.svorc@upjs.sk

\section{Introduction}

Rat models are useful for the study of acid-base and respiratory parameters in preclinical trials, and toxicological studies (Subramanian et al. 2013). Normative data for $\mathrm{pH}$ and arterial blood gases would help identify healthy animals for experiments. However, there are few studies that have investigated the reliability of this tool (De Oliveira et al. 2012). Table 1 summarizes the ranges of $\mathrm{pH}$ and blood gas values in rats reported in several previous investigations. However, the time when the experiments were performed and the synchronization of the animals to the light-dark (LD) cycle were not accounted for in the methodologies of these studies.

Although chronobiological studies investigating the interactions between general anesthesia and circadian rhythms are sparse, all suggest that general anesthesia has a significant effect on vital functions (Dispersyn et al. 2008). However, to date, there is no literature evidence regarding the effect of general anesthesia on $\mathrm{pH}$ and blood gases in arterial blood, and their dependence on circadian rhythmicity or the LD cycle. Chronobiological factors originating from circadian rhythm can be a problem (Reinberg 1986, Sato et al. 2005). Most reported methods do not describe the time of day at which the experiments are performed or the factors responsible for changes in the particular parameters studied. Instead, they have primarily focused on temporally current mechanical and metabolic changes, often irrespective of the functional state of systems in 
a $24 \mathrm{~h}$ period. This can be a problem because the LD cycle is the strongest factor influencing the synchronization of endogenous rhythms in rats.

The choice of anesthetic agent and its influence (particularly on the respiratory and cardiovascular systems) (Haskins et al. 1986, Farver et al. 1986) can be problematic. Changes in the functional efficiency of these systems lead to changes in $\mathrm{pH}$ and blood gas values and, conversely, changes in these parameters influence the functional state of these systems. Similarly, changes in $\mathrm{pH}$ and blood gases also reflect the $24 \mathrm{~h}$ fluctuation in the function of the respiratory and cardiovascular systems. Hence, the reference values for $\mathrm{pH}$ and blood gas values can cause difficulties because $\mathrm{pH}$ and blood gases reflect the current (active or non-active) state of the organism. Results are often compared with mean reference values, often irrespective of their dependence on circadian rhythm.

The specific aim of the present in vivo study, therefore, was to refer to the status of the internal environment, presented by arterial $\mathrm{pH}, \mathrm{pO}_{2}$ and $\mathrm{pCO}_{2}$, under general anesthesia after application of the anesthetic agents pentobarbital (P), ketamine/xylazine $(\mathrm{K} / \mathrm{X})$, and zoletil $(\mathrm{Z})$ in spontaneously breathing rats and their dependence on the LD cycle.

\section{Material and methods}

The present study conformed to the Guide for the Care and Use of Laboratory Animals published by the United States National Institutes of Health (NIH publication number 85-23, revised 1996). The study protocol was approved by the Ethics Committee of the Medical Faculty of Safarik University (Kosice, Slovak Republic) (permission number $2 / 05$ and permission number ŠVPS SR: Ro-4234/15-221).

The present study was performed using female Wistar rats (mean $[ \pm$ SD] weight $310 \pm 20 \mathrm{~g}$ ), three to four months of age after a four-week adaptation to an LD cycle ( $12 \mathrm{~h}$ light: $12 \mathrm{~h}$ dark [intensity of artificial illumination $80 \mathrm{~lx}$ ]; $40 \%$ to $60 \%$ humidity; cage temperature $24{ }^{\circ} \mathrm{C}$; two animals/cage; ad libitum access to food and water). The effect of the light period on the monitored parameters was examined after adaptation to an LD cycle, with the light period from $06: 00 \mathrm{~h}$ to 18:00 h. The effect of the dark period was monitored after adaptation to the inverse setting of the LD cycle (i.e. with the light period from 18:00 $\mathrm{h}$ to $06: 00 \mathrm{~h}$ ).

The animals were divided into three experimental groups according to the anesthetic agent used: group 1 - pentobarbital (40 mg/kg, Pentobarbital, Spofa, Prague), light period $n=11$, dark period $n=8$, intraperitoneal anesthesia; group 2 - ketamine/xylazine (100 mg/kg, Narkamon Spofa, Prague/15 mg/kg, Rometar, Spofa, Prague) intramuscular anesthesia, light period $\mathrm{n}=13$, dark period $\mathrm{n}=11$; and group 3 tiletamine/zolazepame $\quad(30 \mathrm{mg} / \mathrm{kg}, \quad Z$ Zoletil, Virbac, France) intraperitoneal anesthesia, light period $n=18$, dark period $n=26$.

Approximately $20 \mathrm{~min}$ after administration of anesthetic agent, the spontaneously breathing animals were fixed supine to an experimental table. $\mathrm{pH}$ and blood gases were analyzed from blood samples taken from the femoral artery using radiometer ABL 800 Flex (Copenhagen, Denmark) in the Department of Laboratory Medicine, Faculty Hospital Louis Pasteur in Kosice. At assessment of the depth of the anesthesia, in the first phase, we observed the loss of the righting reflexes and in the second phase, reaction to the pain stimulus applied on the paw of the rat simultaneously with cardiovascular response to a painful stimulus. At the movement or muscle tone change or minimal change of rat ECG, next maneuvers were stopped.

\section{Statistical analysis}

The data were analyzed using GraphPad InStat (GraphPad Software, USA) and presented as mean \pm SD. ANOVA was used to detect significant differences within a single end point. The Tukey-Kramer test was used to identify significant differences between groups; $\mathrm{p}<0.05$ was considered to be statistically significant. The experiments were performed during the entire year and the results were averaged independent of season and estrous cycle.

\section{Results}

$p H$

LD differences in arterial $\mathrm{pH}$ were eliminated in $P$ anesthesia, in contrast to $K / X$ (LD difference: $p<0.001$ ) and $Z$ anesthesia (LD difference: $\quad p<0.001$ ) with significantly (Fig. 1) higher mean values in the dark (active) period of the rat regimen day. No significant differences in $\mathrm{pH}$ among the types of anesthesia were detected in the light period of the day. Mean $\mathrm{pH}$ values were significantly higher only in the dark period in $\mathrm{K} / \mathrm{X}$ $(\mathrm{p}<0.001)$ and $\mathrm{Z}$ anesthesia $(\mathrm{p}<0.01)$ versus $\mathrm{P}$ anesthesia (Fig. 1).

For all types of anesthesia in the light period, 
arterial $\mathrm{pH}$ was found to be acidic compared with the calculated mean range reported by other authors (Table 1). In the dark period, the $\mathrm{pH}$ moved into the acidic range in $\mathrm{P}$ anesthesia, from normal values to alkaline in $\mathrm{K} / \mathrm{X}$, and from acidic to normal values in $\mathrm{Z}$ anesthesia.

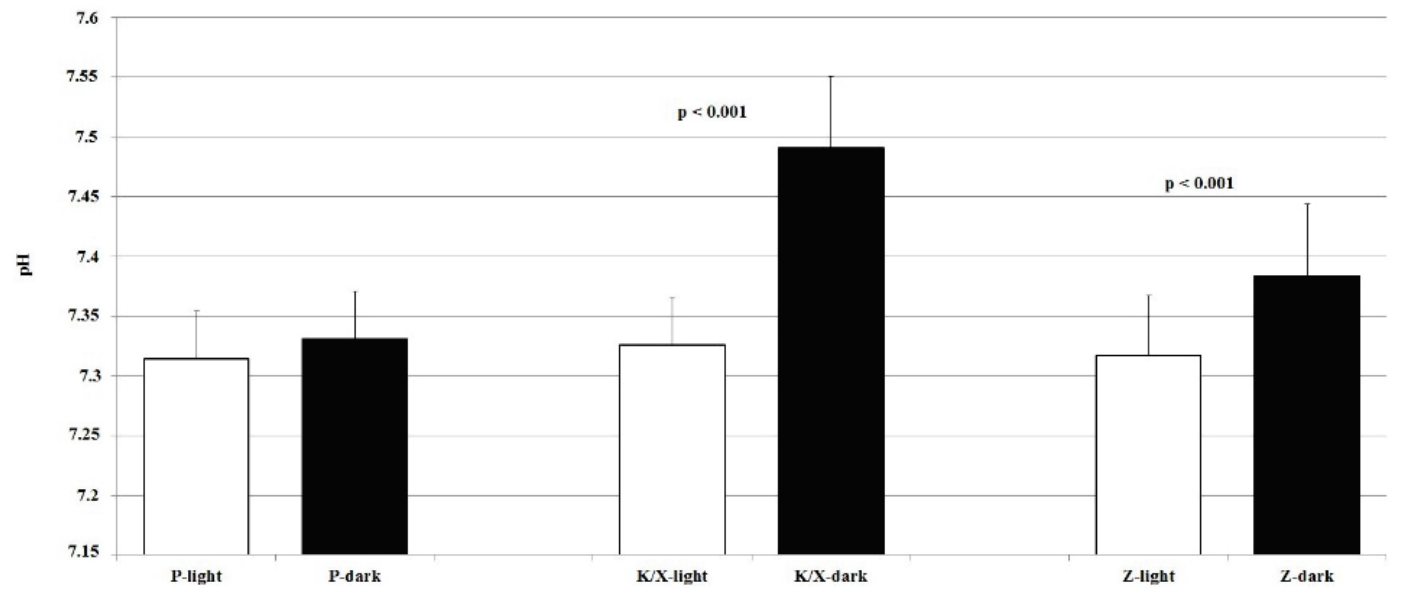

Fig. 1. $\mathrm{pH}$ in the light (white columns) and dark (black columns) periods in pentobarbital (P)-, ketamine/xylazine (K/X)- and zoletil (Z)-anesthetized rats. Data presented as mean \pm SD. $p<0.001$ was considered to be a statistically significant difference between the light and dark periods.

Table 1. Values of $\mathrm{pH}$ and blood gas values in rat arterial blood reported in the literature.

\begin{tabular}{|c|c|c|c|}
\hline Author (year) & pH & $\mathrm{pCO}_{2}(\mathrm{kPa})$ & $\mathrm{pO}_{2}(\mathrm{kPa})$ \\
\hline Lewis et al. (1973) & 7.43 & 5.47 & 12.13 \\
\hline Pepelko and Dixon (1975) & $7.446-7.486$ & $5.24-5.74$ & $11.77-12.71$ \\
\hline Brun-Pascaud et al. (1982) & $7.45-7.49$ & $4.2-4.99$ & $11.26-12.72$ \\
\hline Girard et al. (1983) & $7.46-7.47$ & $4.57-4.71$ & $12.72-13.02$ \\
\hline Hess et al. (1984) & $7.43-7.51$ & $3.33-4.67$ & $12.2-15.4$ \\
\hline Dettmers (1994) & $7.38-7.46$ & $5.19-5.99$ & $9.4-11$ \\
\hline Chi et al. (1996) & $7.27-7.37$ & $4.78-5.77$ & $13.8-17$ \\
\hline Ohoi and Takeo (1996) & - & $4.66-5.32$ & $13.3-17.3$ \\
\hline Schultz (1997) & $7.35-7.45$ & $3.33-5.32$ & $10.6-14.6$ \\
\hline Sun and Wainwright (1997) & $7.40-7.45$ & $4.64-5.32$ & 11.3 \\
\hline Forkel (2004) & & $5.16-6.39$ & $12.85-15.48$ \\
\hline Valenza et al. (2012) & $7.41-7.43$ & $5.18-5.48$ & - \\
\hline Subramanian et al. (2013) & $7.26-7.4$ & $5.05-7.51$ & $10.76-14.60$ \\
\hline Peralta-Ramírez (2014) & $7.2-7.46$ & $5.62-6.20$ & - \\
\hline Luo et al. (2015) & - & $5.58-6.08$ & $10.37-12.19$ \\
\hline
\end{tabular}

$\mathrm{pCO}_{2}$

LD differences in $\mathrm{pCO}_{2}$ were eliminated in $\mathrm{P}$ and $\mathrm{Z}$ anesthesia (Fig. 2). The highest $\mathrm{pCO}_{2}$ values were under $\mathrm{P}$ anesthesia, with more pronounced hypocapnia in $\mathrm{K} / \mathrm{X}$ anesthesia in the dark period (Table 2). In the light period, a significant difference was recorded between $P$ and $Z$ anesthesia $(p<0.001)$, with higher values under $\mathrm{P}$ anesthesia. During the dark period, significant differences between the different types of anesthesia were observed (P vs. K/X [p $<0.001]$; $\mathrm{P}$ vs. $\mathrm{Z}$ $[\mathrm{p}<0.01]$; and $\mathrm{K} / \mathrm{X}$ vs. $\mathrm{Z}[\mathrm{p}<0.001])$. Given that the values reported in Table 1 are considered to be physiological, compared with these ranges, the mean $\mathrm{pCO}_{2}$ reported in this study is in the range of hypercapnia for each type of anesthesia in the light period. The same is true for mean values in the dark period, except $\mathrm{K} / \mathrm{X}$ anesthesia (Table 2). 
$p \mathrm{O}_{2}$

Similar to $\mathrm{pH}$, significant $\mathrm{LD}$ differences in $\mathrm{pO}_{2}$ were found only in $\mathrm{K} / \mathrm{X}(\mathrm{p}<0.001)$ and $\mathrm{Z}$ anesthesia $(p<0.05)$ (Fig. 2). However, it is interesting to note that in all types of general anesthesia used in this study, hypoxia was detected in both light periods in spontaneously breathing rats. In all types of anesthesia used in this study, the mean values were not reached in the light (i.e. non-active) period. The lower value of the reference ranges from Table 1 was obtained in the dark period in $\mathrm{P}$, $\mathrm{K} / \mathrm{X}$ and in $\mathrm{Z}$ anesthesias, and in the light period in $Z$ anesthesia (Table 3). Significant differences were found between $\mathrm{P}$ and $\mathrm{K} / \mathrm{X}(\mathrm{p}<0.001), \mathrm{P}$ and $\mathrm{Z}(\mathrm{p}<0.05)$, and between $\mathrm{K} / \mathrm{X}$ and $\mathrm{Z}$ anesthesia $(\mathrm{p}<0.001)$, with the lowest value in $\mathrm{K} / \mathrm{X}$ anesthesia in the light period.

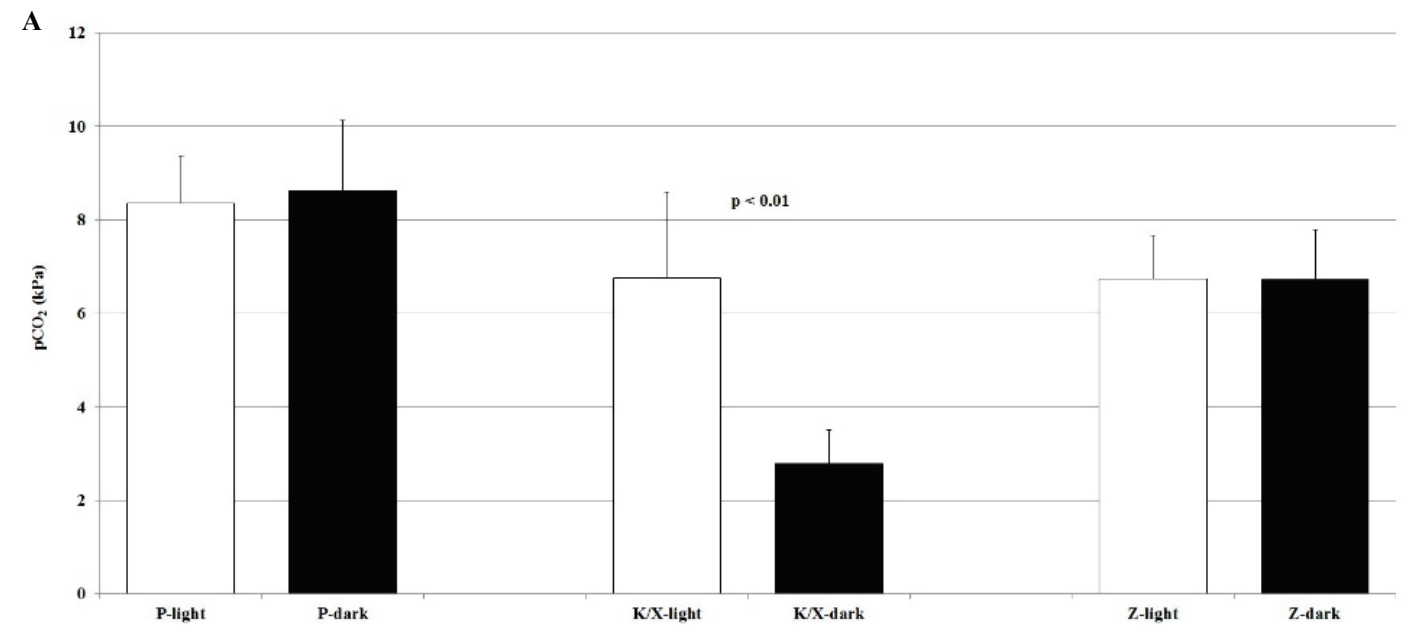

B

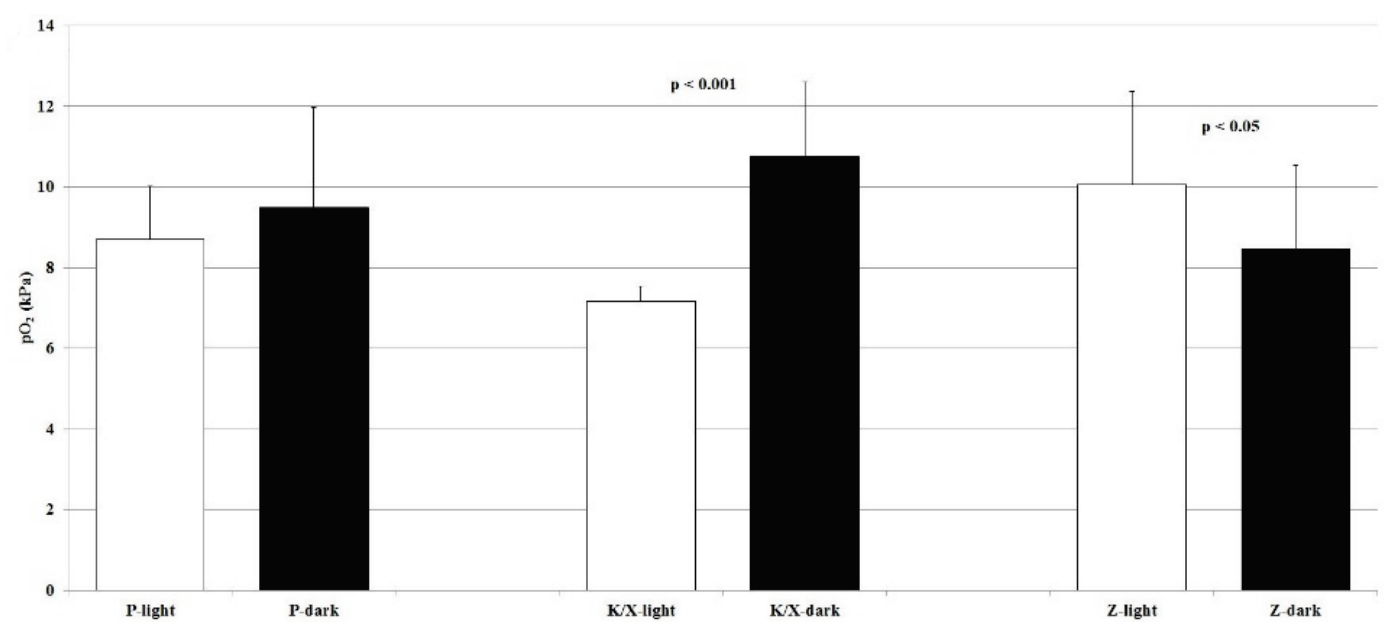

Fig. 2. (A) $\mathrm{pCO}_{2}$ and (B) $\mathrm{pO}_{2}$ in the light (white columns) and dark (black columns) periods in pentobarbital (P)- ketamine-xylazine $(\mathrm{K} / \mathrm{X})$ - and zoletil (Z)-anesthetized rats. Data are presented as mean $\pm \mathrm{SD}$. $\mathrm{p}<0.05, \mathrm{p}<0.01$ and $\mathrm{p}<0.001$ were considered to be a statistically significant difference between the light and dark periods.

Table 2. $\mathrm{pH}$ and blood gas values in arterial blood under selected types of general anesthesia during the light and dark periods of the rat regimen day.

\begin{tabular}{lcccccc}
\hline & \multicolumn{2}{c}{ Pentobarbital } & \multicolumn{2}{c}{ Ketamine/xylazine } & \multicolumn{2}{c}{ Zoletil } \\
Parameter & Light & Dark & Light & Dark & Light & Dark \\
\hline$p H$ & $7.314 \pm 0.04$ & $7.331 \pm 0.04$ & $7.326 \pm 0.04$ & $7.491 \pm 0.06^{* * *}$ & $7.317 \pm 0.05$ & $7.384 \pm 0.06^{* * *}$ \\
$p \mathrm{CO}_{2}(\mathrm{kPa})$ & $8.348 \pm 1.03$ & $8.638 \pm 1.49$ & $6.762 \pm 1.84$ & $2.786 \pm 0.72^{* *}$ & $6.745 \pm 0.93$ & $6.723 \pm 1.07$ \\
$\mathrm{pO}_{2}(\mathrm{kPa})$ & $8.699 \pm 1.33$ & $9.49 \pm 2.48$ & $7.172 \pm 0.37$ & $10.751 \pm 1.84^{* * *}$ & $10.06 \pm 2.31$ & $8.46 \pm 2.08^{*}$ \\
\hline
\end{tabular}

Data presented as mean $\pm \mathrm{SD}$. $* p<0.05, * * p<0.01$, and $* * * p<0.001$ (statistically significant differences between light and dark period). $\mathrm{pCO}_{2}$ - partial pressure of carbon dioxide, $\mathrm{pO}_{2}$ - partial pressure of oxygen. 
Table 3. Ranges in $\mathrm{pH}$ and blood gas values from experiments under selected types of anesthesia during the light and dark periods of the rat regimen day compared with mean range calculated from Table 1.

\begin{tabular}{|c|c|c|}
\hline & Range & Status \\
\hline$p H$ & 7.369 - 7.452 (from Table 1) & \\
\hline Pentobarbital-light & $7.274-7.318$ & Acidosis \\
\hline Pentobarbital-dark & $7.291-7.335$ & Acidosis \\
\hline Ketamine/xylazine - light & $7.286-7.366$ & Acidosis \\
\hline Ketamine/xylazine - dark & $7.431-7.551$ & From normal to alkalosis \\
\hline Zoletil- light & $7.267-7.367$ & Acidosis \\
\hline Zoletil-dark & $7.324-7.444$ & From acidosis to normal \\
\hline $\mathrm{pCO}_{2}$ & $4.752-5.298 \mathrm{kPa}$ (from Table 1) & \\
\hline Pentobarbital - light & $7.32-9.38$ & Hypercapnia \\
\hline Pentobarbital - dark & $7.15-10.13$ & Hypercapnia \\
\hline Ketamine/xylazine - light & $4.92-8.6$ & Normocapnia - hypercapnia \\
\hline Ketamine/xylazine - dark & $2.16-3.6$ & Hypocapnia \\
\hline Zoletil- light & $5.82-7.68$ & Hypercapnia \\
\hline Zoletil-dark & $5.41-7.39$ & Hypercapnia \\
\hline $\mathrm{pO}_{2}$ & $10.521-14.184 \mathrm{kPa}$ (from Table 1$)$ & \\
\hline Pentobarbital - light & $7.36-10.02$ & Hypoxia \\
\hline Pentobarbital-dark & $7.01-11.97$ & Hypoxia - normoxia \\
\hline Ketamine/xylazine - light & $6.8-7.54$ & Hypoxia \\
\hline Ketamine/xylazine - dark & $8.91-12.59$ & Hypoxia - normoxia \\
\hline Zoletil-light & $7.75-12.37$ & Hypoxia - normoxia \\
\hline Zoletil-dark & $6.38-10.54$ & Hypoxia - normoxia \\
\hline
\end{tabular}

\section{Discussion}

The methodological characteristics of this study highlight the potential risks of experimental design, following connection of two aspects. The first aspect is chronobiological aspect, which put a question, what is the status in the monitored parameters in the active (dark) or inactive (light) part of the rat regime day under general anesthesia. The second aspect put a question, what is the initial status of the internal environment, presented by $\mathrm{pH}, \mathrm{pO}_{2}$ and $\mathrm{pCO}_{2}$, under general anesthesia and what is the effect of 3 different, commonly used anesthetics for production of general anesthesia in experimental practice, on the monitored parameters.

Based on our results, we may see the same effect of selected anesthetics, but only in the light part of the rat regime day (Table 3 ). If we are comparing our results with the presented values in Table 1, this may cause a methodological problem. Only hypothetically, but logically, can be assumed that results in Table 1 are from experiments, which were performed during working hours (i.e. in the light [inactive], part of the rat regimen day). It means that the values presented in Tables 1 are comparable with our results only from the light (inactive) part of the day. In the dark (i.e. active) part of the rat regimen day, the values - although significantly different among the individual types of general anesthesia - may be within the normal ranges. Because, we do not have any relevant literary data about the arterial $\mathrm{pH}, \mathrm{pO}_{2}$ and $\mathrm{pCO}_{2}$ values from the active (dark) part of the rat regime day, or from the circadian fluctuation of the acid-base balance, so in this case, comparisons can be irrelevant.

Overall, under all types of general anesthesia, but only in the light (inactive) part of the rat regime day, unambiguous acidosis, hypoxia and hypercapnia were induced. There are several explanations for the decrease 
in $\mathrm{pH}, \mathrm{pO}_{2}$ and increase of $\mathrm{pCO}_{2}$. For example, significant respiratory depression results in lower $\mathrm{pH}$ and higher $\mathrm{pCO}_{2}$ (Kaczmarczyk and Reinhardt 1975, BrunPascaud et al. 1982). Another factor may be the significant decrease in rectal temperature observed after anesthetic administration (Svorc et al. 2017), which may be the cause of decreased $\mathrm{pH}$ and changes in the partial pressures of blood gases (Gaudy et al. 1994).

$\mathrm{P}$ anesthesia produces a more acidic internal environment than $\mathrm{K} / \mathrm{X}$ and $\mathrm{Z}$ anesthesia and $\mathrm{pH}$ values were the lowest in both lighted parts of the rat regimen day. Using $\mathrm{P}$ anesthesia, also hypoxia and hypercapnia were induced, regardless of the synchronization of the animals to the LD cycle and, therefore, it is not possible to monitor periodic changes in the functions of the individual systems that are primarily dependent on changes in extracellular $\mathrm{pH}$ and/or blood gases.

Loss of LD differences under $\mathrm{P}$ anesthesia in all measured parameters may be associated with affecting of a circadian pacemaker in the hypothalamus or with a direct effect on the cardiovascular and respiratory systems, that are responsible for current changes in $\mathrm{pH}$, $\mathrm{pO}_{2}$ and $\mathrm{pCO}_{2}$. There are relatively few literature about the effect of pentobarbital on circadian rhythms in the rat. For example, pentobarbital induced both advanced and delayed phase shifts in the circadian rhythm of locomotor activity in SK mice; however, no phase shifts were observed at any circadian time with pentobarbital in C57BL mice (Ebihara et al. 1988). Furthermore, pentobarbital-induced phase shifts were not due to increasing activity levels (Ebihara and Hayakawa 1990). In a study by Mihara et al. (2012), pentobarbital showed no phase effects on either melatonin secretion or locomotor activity in rats, regardless of the timing of administration.

But also hypoxia can modify the circadian oscillation of important variables, such as body temperature and metabolism, and may lead to the expectation that the daily rhythms of many functions are disrupted by hypoxia according to their relationships and connection with the primary variables (Mortola 2007): it appears that this effect is evident in rats under $\mathrm{P}$ anesthesia. Loss of LD differences in $\mathrm{pH}$ under $\mathrm{P}$ anesthesia may be the result in diminished either the activity of the buffer systems or in inhibition of the regulatory mechanisms involved in maintaining isohydria, independently of light and dark alternation. Since these changes occurred relatively quickly (within $20 \mathrm{~min}$ ), we suppose a direct effect on the cardiovascular and respiratory system.

Consequently, the effect of initial hypoxia and hypercapnia on the circadian rhythms of oxygendependent systems, after administration of selected anesthetics, can significantly influence the final results. In this regard, $\mathrm{K} / \mathrm{X}$ and $\mathrm{Z}$ anesthesia may be more appropriate anesthesia because arterial blood $\mathrm{pH}$ fluctuates within the range of isohydria. This assumption is valid only if the rat experiments are performed under $\mathrm{K} / \mathrm{X}$ and $\mathrm{Z}$ anesthesia and in their dark (i.e. active) part of the rat regimen day.

From chronobiological view we concluded, that the LD differences (circadian fluctuation) in the observed parameters are not preserved under general anesthesia after the application of the P. In this regard, P anesthesia is an inappropriate type of general anesthesia in rat experiments, because disturbs LD differences in contrast to $\mathrm{K} / \mathrm{X}$ and $\mathrm{Z}$ anesthesia. The second view is the status of the internal environment $\left(\mathrm{pH}, \mathrm{pO}_{2}\right.$ and $\left.\mathrm{pCO}_{2}\right)$ under general anesthesia. Our results show that also from this point of view, $\mathrm{P}$ anesthesia is inappropriate, because causes serious asphyxia in both lighted periods of rat regime day.

Based on the results of this study, we conclude that general anesthesia has an impact on LD differences in arterial $\mathrm{pH}$ and blood gas values. This fact should be taken into account and experiments should be started with $\mathrm{pH}, \mathrm{pO}_{2}$, and $\mathrm{pCO}_{2}$ in the normal range. Even at the beginning of an experiment, an altered internal environment can impact the activity of systems whose functions are primarily dependent on $\mathrm{pH}$ and/or on the partial pressures of respiratory gases. Therefore, this information may be useful for future experimental rat studies, but more qualitative studies must be carried in order to close this knowledge gaps.

\section{Conflict of Interest}

There is no conflict of interest.

\section{Acknowledgements}

This work was supported by the Funding Agency VEGA of Ministry of Education of Slovak Republic - 1/0423/11. 


\section{References}

BRUN-PASCAUD M, GAUDEBOUT C, BLAYO MC, POCIDALO JJ: Arterial blood gases and acid-base status in awake rats. Respir Physiol 48: 45-57, 1982.

CHI OZ, WEI HM, TSE J, KLEIN SL, WEISS HR: Cerebral microregional oxygen balance during chronic versus acute hypertension in middle cerebral artery occluded rats. Anesth Analg 82: 587-592, 1996.

DE OLIVEIRA RB, DEMACEDO DV, SANTOS GB, ARCANJO AM: Reliability of the electrocardiogram in normal rats. Int J Exerc Sci: Conference Proceedings 1: S77, Article 62, 2012.

DETTMERS CH, HAGENDORFF A, KASTRUP A, LUDERITZ B, HARTMANN A: An experimental model for hemodynamic evaluation of arrhythmias in rats. Cerebrovasc Dis 4: 309-313, 1994.

DISPERSYN G, PAIN L, CHALLET E, TOUITOU Y: General anesthetics effects on circadian temporal structure: an update. Chronobiol Int 25: 835-850, 2008.

EBIHARA S, GOTO M, OSHIMA I: The phase-shifting effects of pentobarbital on the circadian rhythm of locomotor activity in the mouse: strain differences. Brain Res 28: 404-407, 2008.

EBIHARA S, HAYAKAWA H: Pentobarbital-induced phase shifts of circadian rhythms of locomotor activity are not mediated through stimulated activity in mice. Experientia 46: 1023-1026, 1990.

FARVER TB, HASKINS SC, PATZ JD: Cardiopulmonary effects of acepromazine and of the subsequent administration of ketamine in the dog. Am J Vet Res 47: 631-635, 1986.

FORKEL J, CHEN X, WANDINGER S, KESER F, DUSCHIN A, SCHWANKE U, FREDE S, MASSOUDY P, SCHULZ R, JAKOB H, HEUSCH G: Responses of chronically hypoxic rat hearts to ischemia: $\mathrm{K}_{\mathrm{ATP}}$ channel blockade does not abolish increased RV tolerance to ischemia. Am J Physiol Heart Circ Physiol 286: H545-H551, 2004.

GAUDY JH, SICARD JF, MANEGLIA R, ATOS MQ: Effects of halothane on paCO2 variability, acid-base-balance and ventilation induced hypoxia in the rat. Can J Anaesth 41: 347-352, 1994.

GIRARD P, BRUN-PASCAUD M, POCIDALO JJ: Acid-base status of awake rats after cannulation of aorta and vena cava. Kidney Int 24: 795-799, 1983.

HASKINS SC, PATZ JD, FARVER TB: Xylazine and xylazine-ketamine in dogs. Am J Vet Res 47: 636-641, 1986.

HESS L, DVOŘÁČEK I, SVOBODNÍK J: Chapter 3, Rats (Rodentia). In: Anesthesia of Laboratory Animals. Avicenum, Prague, 1988, p 158.

KACZMARCZYK G, REINHARDT HW: Arterial blood gas tensions and acid-base status of Wistar rats during thiopental and halothane anesthesia. Lab Anim Sci 25: 184-190, 1975.

LEWIS LD, PONTEN U, SIESJO BK: Arterial acid-base changes in un-anesthetized rats in acute hypoxia. Respir Physiol 19: 312-321, 1973.

LUO X, YIN Y, YOU G, CHEN G, WANG Y, ZHAO J, WANG B, ZHAO L, ZHOU H: Gradually increased oxygen administration improved oxygenation and mitigated oxidative stress after resuscitation from severe hemorrhagic shock. Anesthesiology 123: 1122-1132, 2015.

MIHARA T, KIKUCHI T, KAMIYA Y, KOGA M, UCHIMOTO K, KURAHASHI K, GOTO T: Day or night administration of ketamine and pentobarbital differentially affect circadian rhythms of pineal melatonin secretion and locomotor activity in rats. Anesth Analg 115: 805-813, 2012.

MORTOLA JP: Hypoxia and circadian patterns. Respir Physiol Neurobiol 158: 274-279, 2007.

OHOI I, TAKEO S: Involvement of superoxide and nitric oxide in the genesis of reperfusion arrhythmias in rats. Eur J Pharmacol 306: 123-131, 1996.

PEPELKO WE, DIXON GA: Arterial blood gases in conscious rats exposed to hypoxia, hypercapnia, or both. $J$ Appl Physiol 38: 581-587, 1975.

PERALTA-RAMÍREZ A, RAYA AI, PINEDA C, RODRÍGUEZ M, AGUILERA-TEJERO E, LÓPEZ I: Acid-base balance in uremic rats with vascular calcification. Nephron Extra 4: 89-94, 2014.

REINBERG A: Circadian rhythms in effects of hypnotics and sleep inducer. Int J Clin Pharmacol Res 6: 33-44, 1986.

SATO Y, SEO N, KOBAHASHI E: The dosing-time dependent effects of intravenous hypnotics in mice. Anesth Analg 101: 1706-1708, 2005. 
SCHULTZ JJ, HSU AK, GROSS GJ: Ischemic preconditioning and morphine-induced cardioprotection involve the delta (ס)-opioid receptor in the intact rat heart. J Mol Cell Cardiol 29: 2187-2195, 1997.

SUBRAMANIAN RK, SIDHARTHAN A, MANEKSH D, RAMALINGAM L, SOOSAI MANICKAM A, KANTHAKUMAR P, SUBRAMANI S: Normative data for arterial blood gas and electrolytes in anesthetized rats. Indian J Pharmacol 45: 103-104, 2013.

SUN W, WAINWRIGHT CL: The role of nitric oxide in modulating ischaemia-induced arrhythmias in rats. J Cardiovasc Pharmacol 29: 554-562, 1997.

SVORC P, BACOVA I, GRESOVA S, SVORC P JR: Chronobiological perspectives on myocardial electrophysiological parameters under three types of general anaesthesia in a rat model. Biol Rhythm Res 48: 343-351, 2017.

VALENZA F, PIZZOCRI M, SALICE V, CHEVALLARD G, FOSSALI T, COPPOLA S, FROIO S, POLLI F, GATTI S, FORTUNATO F, COMI GP, GATTINONI L: Sodium bicarbonate treatment during transient or sustained lactic acidemia in normoxic and normotensive rats. PLoS One 7: e46035, 2012. 